\title{
OS BENEFÍCIOS DO ÓLEO DE MELALEUCA NA ACNE GRAU II E III: uma revisão de literatura
}

\author{
Babieli Corsini BACCOLI ${ }^{1}$
}

Daniela Alves dos REIS ${ }^{2}$

Michelle Diniz SCIANI ${ }^{3}$

Alexandra Azevedo CARVALHO ${ }^{4}$

${ }^{1}$ Aluna do curso de Pós Graduação em Cosmetologia e Estética Integral / UninCor
${ }^{2}$ Aluna do curso de Pós Graduação em Cosmetologia e Estética Integral / UninCor
${ }^{3}$ Aluna do curso de Pós Graduação em Cosmetologia e Estética Integral / UninCor
${ }^{4}$ Coordenadora, Orientadora e Professora do Curso de Cosmetologia e Estética Integral / UninCor

Recebido em: 27/01/2015 - Aprovado em: 17/06/2015 - Disponibilizado em: 15/07/2015

\begin{abstract}
RESUMO
A acne é a mais comum das doenças crônicas do folículo pilossebáceo da pele humana, causada por múltiplos fatores e que leva ao aparecimento de algumas lesões características. Há uma variedade de acne, a mais comum é a acne vulgar classificada como inflamatória e não inflamatória. A Melaleuca alternifólia é uma árvore australiana da qual se extrai o óleo de melaleuca. O óleo da melaleuca empregado para o tratamento da acne, é uma alternativa tópica bastante utilizada, devido as propriedades antibacteriana e antioxidantes que a planta possui. Assim um tratamento com o melhor resultado na acne contendo o óleo essencial da planta Melaleuca, onde possui propriedades químicas e terapêuticas, extremamente eficiente no combate de uma ampla variedade de micro-organismos, entre os quais o Propionibacterium acnes que origina a acne. O objetivo é realizar estudo sobre os benefícios do Óleo de Melaleuca no Tratamento Estético da Acne nos grau II e III. Sendo realizado um levantamento bibliográfico sobre o tema proposto em livros, artigos científicos, revistas da área de saúde e outros. Pode ser considerado um agente seguro que combate as infecções bacterianas, possuindo boas propriedades de penetração tecidual para o tratamento da acne, assim podendo ser empregado em formulações cosméticas auxiliando nos tratamentos estéticos.
\end{abstract}

Palavras - chave: Acne. Melaleuca. Tratamento.

\begin{abstract}
Acne is the most common chronic diseases of the pilosebaceous follicle of human skin, caused by multiple factors and that leads to the appearance of some characteristic lesions. There are a variety of acne, the most common is acne vulgaris classified as non-inflammatory and inflammatory. The alternifólia is an Australian tree Melaleuca from which extracts the oil of melaleuca. Melaleuca oil employed for the treatment of acne, is an alternative topical enough used, due to its antibacterial and antioxidant properties that the plant has. Thus a treatment with the best result in acne containing the essential oil of Melaleuca plant, where chemical and therapeutic properties, extremely efficient in combating a wide variety of microorganisms including Propionibacterium acnes which leads to acne. The goal is to conduct study on the benefits of tea tree oil in treating Acne Aesthetic in grade II and III. Being carried out a bibliographic survey about the proposed theme in books, scientific articles, healthcare magazines and others. Can be considered an insurance agent that fights bacterial infections, possessing good tissue penetration properties for the treatment of acne, so being able to be employed in cosmetic formulations and aidingin aesthetic treatments.
\end{abstract}

Keywords: Acne. Melaleuca. Treatment.

\section{Introdução}

A acne é uma das doenças mais comuns que afligem a humanidade. Devido ao aumento dos números de casos, a procura por um tratamento efetivo, é que seja bem tolerado pelo paciente. 
A etiologia da acne esta profundamente inter-relacionada com a produção de sebo pelas glândulas sebáceas, hiperqueratinização folicular, colonização bacteriana do folículo e a liberação de mediadores da inflamação no folículo e derme adjacente (RUZANY, 2004).

A acne por ser um tema muito abordado, possui diversos tipos de tratamentos, sendo que o uso das plantas com propriedades antibacterianas e antioxidantes, como a Melaleuca alternifólia, tem sido muito procurado (BATISTUZZO, 2000).

A melaleuca é uma alternativa tópica bastante utilizada nesse tipo de tratamento. Esse fármaco reduz a irritação da pele e tem uma atividade comedolítica e anti-inflamatória apropriada, além de apresentar menos efeitos colaterais (HEMIELEWSKI, 2008).

O óleo essencial de Melaleuca é conhecido como Tea Tree (árvore do chá), de espécie arbórea nativa da Austrália, a Melaleuca Alternifólia, possui grandes propriedades medicinais ( CASTRO et al, 2005 apud GARCIA et al.; 2009).

Dentre as suas grandes propriedades, destacam seu poder bactericida, cicatrizante, expectorante, fungicida, antiinfeccioso, balsâmico, antiinflamatório, anti-séptico, antiviral, febrífugo, inseticida, imunoestimulante, diaforético, parasiticida e vulnerário (MALUF, 2009)

O objetivo deste artigo é mostrar a Eficácia do Óleo de Melaleuca no Tratamento Estético da Acne nos grau II e III.

\section{Desenvolvimento}

\subsection{Pele}

A pele exerce uma via atrativa e acessível para administração de substâncias, principalmente em função dos problemas agregados com outras rotas como a via oral e parenteral. Apresentam vantagens como o efeito sistêmico e a possibilidade de vetorização somente para a área afetada, quando o efeito tópico é desejado (GUTERRES et al., 2007).

É o órgão mais amplo do corpo humano e equivale cerca de $5 \%$ do peso total, apresentando variações de espessura e valores de $\mathrm{pH}$ de acordo com cada região (PEYREFITTE et al., 1998).

Considerada como órgão, possui arquitetura como um todo, mostrando múltiplas e precisas funções. Constitui, antes de tudo, a primeira linha de defesa contra agressões do meio ambiente, não sendo uma barreira insuperável (RANGEL, 1998). 
A pele humana é estruturada de três camadas, sendo estas, a epiderme celular, sedimentada e avascular na superfície; a derme subjacente formada por tecido conjuntivo na camada média e a hipoderme, tecido conjuntivo adiposo na camada profunda (HERNANDEZ; MERCIER-FRESNEL, 1999).

\subsection{Acne}

A acne é uma das doenças de pele mais comuns em todo o mundo. Tratase de uma doença frequente, autolimitada, multifatorial que acomete os folículos sebáceos (SETTE et al., 2009).

O sebo é uma mistura de substâncias lipofílicas. O papel de cada uma destas substâncias na patogênese da acne não é totalmente conhecido, mas há evidências de que alterações na composição ou na quantidade da secreção sebácea colaborariam no desenvolvimento da doença por alterar tanto a queratinização do ducto glandular quanto a proliferação bacteriana. (MARQUES, 2000).

Definida como uma patologia inflamatória crônica de etiologia multifatorial, que ataca a unidade pilossebácea. Pode ser caracterizada pela presença de erupções foliculares iniciadas por "comedões", que desencadeiam reações inflamatórias, levando a evolução das lesões com formação de papulas, pústulas e cistos (PAWIN et al., 2004).

De fácil diagnóstico, não compromete gravemente a saúde do indivíduo, mas pode prejudicar o bem-estar e o desenvolvimento emocional, levando à diminuição da auto-estima e a modificação comportamental (TEIXEIRA; FRANÇA, 2007).

Segundo Sampaio; Rivitti (2001), a acne é classificada clinicamente em quatro graus:

- Grau I: É a forma mais leve da acne. Não inflamatória, pois a colonização pela bactéria $P$. acnes ainda não aconteceu. Caracterizada pela presença de comedões (cravos) fechados ou abertos (HABIF, 2005).

- Grau II: É a acne inflamatória ou pápulopustulosa, quando as pápulas (lesões sólidas) e pústulas (lesões líquidas de conteúdo purulento) se associam aos comedões. Uma pápula ocorre quando há uma ruptura na parede folicular. É consequência de um comedão inflamado (CAMPBELL et al., 2003).

- Grau III: Acne nódulo-abscedante, quando se somam os nódulos (lesões sólidas mais exuberantes). Uma lesão completamente inflamada pode por vezes originar um colapso ou romper, ocasionando uma inflamação severa na 
pele circundante e, às vezes, envolver folículos vizinhos. Essas lesões são chamadas de nódulos ou cistos (ACNE, 2008).

- Grau IV: É a chamada acne conglobata, na qual há formação de abcessos e fístulas. É uma forma da acne cística crônica, intensamente inflamatória onde as áreas relacionadas contêm uma mistura de comedões duplo (dois cravos pretos que se comunicam sob a pele), pápulas, pústulas, abscessos e cistos comunicantes (GONTIJO et al., 2003).

Segundo Sampaio; Bagatin (2008), a acne sempre deve ser tratada, o mais precocemente possível, independente da idade do paciente, evitando assim, a evolução para as formas inflamatórias que podem deixar cicatrizes e desencadear repercussões psicossociais sérias, com impacto negativo na qualidade de vida desses indivíduos.

O tratamento depende da gravidade da acne a qual se relaciona com o aspecto físico, efeitos psicológicos, duração da moléstia, insucesso com tratamentos anteriores e presença de cicatrizes (LEBWOHE et al., 2004).

2.3 Tratamento da Acne

Antes da década de 1940 não havia tratamento efetivo para a acne. A partir deste período, passaram a usar, por via sistêmica, os quimioterápicos e antibióticos como as tetraciclina, eritromicina, sulfas e os corticóides. Já entre 1960 e 1990, produtos tópicos eficazes foram sendo introduzidos no tratamento da acne vulgar, tais como peróxido de benzoila (1965), possui ação antimicrobiana com redução da colonização dos folículos pilosos pelo Propionibacterium acnes, retinóides como a tretinoína (1972), possui ação anti inflamatória e também previnem a formação de comedões por meio de normalização da descamação do epitélio folicular, antibióticos como a eritromicina e a clindamicina (1983), devido a supressão da proliferação da bactéria Propionibacterium acnes nos folículos pilosos afetados, com a redução da inflamação local e ácido azeláico (1985), possui as ações dos retinóides citados acima, porém pode ser utilizados por gestantes e lactantes, não oferecendo riscos as mesmas (SAMPAIO; BAGATIN, 2008).

Para o tratamento da acne grau I pode ser administrado tretinoína, isotretinoína, adapaleno ou ácido azeláico, medicamentos que tem como objetivo os efeitos antiinflamatórios, anticomedogênico e comedolítico. $\mathrm{Na}$ acne grau II, podem ser utilizados antibióticos por via oral como tetraciclina, minocilina 
ou sulfa, além de medicamentos contendo antimicrobianos tópicos, como peróxido de benzoíla, eritromocina ou clindamicina sob a forma de gel ou loção alcoólica. Nos graus III e IV utilizam-se os medicamentos descritos anteriormente ou a monoterapia sistêmica com isotretinoína oral. (MENESES; BOUZAS, 2009).

Outras alternativas são os produtos originados de plantas fitoterrápicas, que também tem sido utilizado no tratamento da acne vulgar.

Dentre os tratamentos fitoterápicos antiacnéicos, o óleo de melaleuca $(\mathrm{OM})$ é o mais citado, inclusive pela Academia Americana de Dermatologia (STRAUSS et al., 2007).

Tratamentos estéticos indicados para a acne podem ser associados à terapêutica médica, com combinações que utilizam princípios ativos, manobras manuais, e também o uso de equipamentos eletroterápicos atuando nas diferentes lesões, contribuindo assim para uma melhora significativa do quadro (BAUMANN, 2004).

Os princípios básicos para montar um protocolo de tratamento da acne vulgar devem ser ajustados individualmente obedecendo alguns passos que serão destacados a seguir: higienizar; esfoliar; emoliência; extração; equilíbrio do $\mathrm{pH}$ cutâneo; tratamento; finalização
(HOCHHEIM, L.; DALCIN, P.C.; PIAZZA, 2010).

\section{4 Óleo de Melaleuca}

Os óleos essenciais são usados a mais de 6000 anos atrás. O óleo essencial de Melaleuca é obtido da Tea Tree, que significa arvore do chá, é comum na região de New South Wales na Austrália (PEREIRA et al., 2009).

É obtido por destilação por arraste a vapor ou hidrodestilação das folhas, onde se tem os seguintes constituintes químicos: terpenos (cineno, terpeno e cimeno): terpineol (tepinen-4-ol), sesquiterpenos e cineol onde estão relacionados com sua atividade antimicrobiana principalmente antifúngica e antibacteriana (SIMÕES et al., 2002 apud GARCIA et al., 2009).

Estudos relacionados a fatores históricos relatam que tribos aborígenes da Oceania utilizavam o óleo extraído de suas folhas e o misturavam com lama, formando uma espécie de pasta que era utilizada como cicatrizante em cortes e antiinflamatório nas infecções cutâneas (AZEVEDO, 2002).

O óleo de melaleuca é também um óleo essencial das folhas, a Melaleuca alternifolia Cheel, que tem sido usado terapeuticamente por mais de 80 anos. Esta 
planta encontra-se disponível em outros locais como Europa, América do Norte e, inclusive, no Brasil (CARSON et al., 2006).

O óleo de melaleuca possui propriedades antissépticas, antifúngicas e parasiticidas naturais, ficando assim mundialmente conhecido (AZEVEDO, 2002).

A constituição química do óleo essencial das folhas de $M$. alternifólia é conhecida, sendo composto por uma mistura complexa de mono e sesquiterpenos, e álcoois terpênicos, com mais de 100 componentes químicos isolados (RUSSEL et al., 2003).

As propriedades do óleo são regulamentadas por um padrão internacional (ISO 4730:2004), que especifica uma concentração mínima e/ou máxima de 14 componentes. Um dos componentes, reconhecidamente ativo, presente no OM, o terpinen-4-ol, e o principal responsável pela ação terapêutica. Segundo o padrão ISO, o óleo deve conter no mínimo 30\% de terpinen-4-ol. Por outro lado, o teor de 1,8-cineol no óleo deve ser no máximo de $15 \%$ (MONDELLO et al., 2006).

$$
\begin{aligned}
& \text { O óleo de Melaleuca é } \\
& \text { considerado como tendo qualidade } \\
& \text { superior, quando contem entre } 2 \text { a } 5 \% \text { de } \\
& \text { cineol e de terpinen-4-ol entre } 40 \text { a } 47 \%
\end{aligned}
$$

(WILLIANS et al, 1990 apud SIMÕES et al., 2002).

Dentre as suas grandes propriedades, destacam seu poder bactericida, cicatrizante, expectorante, fungicida, antiinfeccioso, balsâmico, antiinflamatório, anti-séptico, antiviral, febrífugo, inseticida, imunoestimulante, diaforético, parasiticida e vulnerário (MALUF, 2009).

Devida a sua ação antimicrobiana, anti-séptica, despigmentante e além de ser um conservante natural, o óleo de melaleuca tem sido empregado em formulações. Pode ser incorporado a cremes, loções, sabonetes e xampus anti-sépticos, produtos para a limpeza da pele em especial a oleosa, demaquilantes, after shaves, pós depilatórios, desodorantes, xampus para cabelos oleosos ou com caspa, entre outros (CHRISTOPH et al., 2001 apud GARCIA et al., 2009).

$\begin{array}{rccc}\mathrm{O} & \text { óleo } & \text { tem } & \text { ampla } \\ \text { aplicabilidade nos produtos } & \text { como: }\end{array}$ antiacne, anti-sépticos, desinfetantes, antifúngicos, produtos capilar, higiene oral e pessoal, desodorantes, queimaduras, picadas de inseto, póssol, produtos veterinários, aromaterapia e flavorizantes (SOUZA; ANTUNES, 2009). 
2.5 Indicações

Tem ações anti-séptica, desinfetante, cicatrizante, bacteriostática, germicida, antifúngica, imunoestimulante, expectorante, anticaspa (MALUF, 2009).

Como fitoterápico pode ser usado para queimaduras, acne, infecções virais e fúngicas (herpes, furúnculos, pé de atleta), infecções ginecológicas (candidíase), picadas de insetos, gengivites, aftas, piorréia, psoríase, impetigo, em irritação cutânea e erupções diversas. Em fitocosmética é indicado para tratamento da caspa e da acne (MARQUES, 2000).

Tea Tree Oil é usado em shampoos, condicionadores, cremes, loções, sabonetes, em óleos para uso tópico, em géis, em produtos para assepsia cirúrgica. Germicida: capaz de eliminar vários microorganismos, alguns vírus (herpes), bactérias e fungos, sem causar irritação nem inibir o crescimento e rejuvenescimento normal das células. Grande poder solvente e penetrante: ajuda a eliminar acne (GARCIA et al., 2009).

É imprescindível que o óleo essencial da melaleuca não seja tomado por via oral. Deve ser usado apenas externamente e de preferência diluído, vez que em alguns casos raros, o contato direto sobre a pele foi associado ao desenvolvimento de dermatite de contato alérgica (BASSOLE; JULIAN, 2012).

O óleo é obtido das folhas e dos ramos terminais. Contém alfa-pineno, terpineol, terpinenos, limoneno e cineol entre outros constituintes (BATISTUZZO, 2000). As análises revelaram que a Melaleuca em função das suas propriedades químicas e terapêuticas, é extremamente eficiente no combate de uma ampla variedade de microorganismos, entre os quais o Propionibacterium acnes que origina a acne (WILLIANS apud SIMÕES ET al, 2002, p.8)

\subsection{Contra Indicações}

Existem poucos efeitos adversos do uso tópico do óleo de melaleuca (em baixas concentrações), o mais comum é a dermatite de contato (HÁLCON, 2004).

\section{Metodologia}

Foi realizado um levantamento bibliográfico sobre o tema proposto em livros, artigos científicos, revistas da área de saúde e outros. 


\section{Discussão}

O tratamento da acne visa minimizar a formação de cicatrizes, melhorar a aparência, a autoestima e o relacionamento daquele indivíduo que encontra-se sob isolamento social, prevenindo ou tratando de lesões já instaladas, diminuindo o desconforto físico desencadeado pelas lesões ( HABIF, 2005).

Segundo Strauss et al., (2007); Hochheim; Dalcin; Oiazza, (2010), de 80\% da população juvenil acometida por algum tipo de acne, principalmente entre as pessoas do sexo feminino, apenas um número insignificante procura um dermatologista para indicar o melhor tratamento. Podendo ser realizado com medicamentos tópicos ou sistêmicos, que são classificadas em categorias de medicamentos prescritos ou não prescritos.

Os procedimentos para tratamento da acne deverão ser iniciados e ministrados de acordo com o tipo de lesão e o grau de comprometimento (CAMPBELL et al., 2003; SAMPAIO; BAGATIN, 2008).

Quanto às variáveis clínicodermatológicas, observou-se predomínio das formas leves de acne (graus I e II) e, conseqüentemente, de lesões comedonianas e papulopustulosas em detrimento das formas mais graves. Esses achados estão de acordo com a literatura especializada (SÁ, 2000; TEIXEIRA; FRANÇA, 2007).

A correta limpeza da pele é de fundamental importância, para tanto, é recomendado o uso de sabonetes sem óleo e loção adstringente. Para atenuar a congestão facial é indicado o uso de mascará emoliente. No tratamento da acne são extremamente úteis as preparações antissépticas e adstringentes (PEYREFITTE; MARTINI; CHIVOT, 1998; MODELLO et al., 2006).

Os autores Sampaio; Rivitti, (2001); Simões et al., (2002); Maluf, (2009) descobriram que ambos os tratamentos reduziram o número de lesões tanto não-inflamatórias como inflamatórias. Embora o grupo com peróxido de benzoíla tenha tido um desempenho significativamente melhor e com menos oleosidade na pele, o grupo tratado com óleo de melaleuca apresentou um início de ação mais lento e demonstrou menos efeitos adversos, como menor prurido e ressecamento.

O óleo de melaleuca pode ser incorporado como ingrediente ativo em formulações tópicas utilizadas para tratamento de diversas infecções cutâneas, dentre elas, a acne (HERNANDEZ; 
MERCIER-FRESNEL, 1999; CARSON et al., 2006).

Segundo De Santi (2003), o óleo pode ser apresentado na forma hidrossolúvel e lipossolúvel. Hidrossolúvel é a característica dos produtos que podem ser dissolvidos em água. Assim, o óleo essencial de melaleuca pode ser desenvolvido para formulações límpidas por se tratar de uma microemulsão aquosa sob a forma de gel antiacne, sabonete líquido antibacteriano ou gotas. Já a versão lipossolúvel, por se tratar de substância altamente solúvel na presença de lipídeos e gorduras, além da indicação para o tratamento da acne, pode ser utilizada como antisséptico e antifúngico na forma de sabonete e loção.

O óleo possui características terapêuticas interessantes contra determinadas patologias como ação antiacne, onicomicoses, dermatite, eczema, dor de dente, mau hálito, dentre outros (PRIEST \& PRIEST,2002; ANDRADE et al., 2003 apud GARCIA et al., 2009).

Sua constituição química é bem conhecida, composto de hidrocarbonetos terpênicos sendo o terpinen-4-ol, o principal responsável por suas propriedades medicinais, principalmente antifúngicas, anti-inflamatórias, antisépticas e antibacterianas, garantindolhe importância comercial há mais de 60 anos (SIMÕES et al., 2002; CARSON HAMMER; RILEY., 2006; GARCIA et al., 2009).

\section{Conclusão}

A acne embora seja o resultado de uma inflamação na pele que caracteriza devido ao aumento da secreção das glândulas sebáceas possibilitando a formação de uma espécie de sebo, pode ser classificada como inflamatória e não inflamatória. É considerada como uma doença natural na adolescência e raramente persiste na fase adulta, ela ocorre mais frequentemente na fase da puberdade devido as disfunções hormonais.

Estudos relacionados ao tratamento da acne com óleo de melaleuca, resulta em um tratamento fitoterápico eficaz, devido sua ação germicida, bacteriostática, fungistática, antimicrobiana e anti-inflamatória devido a associação da ação antibacteriana que inibe a proliferação de diversos tipos de microorganismos, entre os quais as bactérias associadas à acne.

É importante focar que em alguns casos é necessário procurar um profissional dermatologista para acompanhamento, dependendo do grau da acne e a gravidade das lesões na pele.

O óleo de melaleuca mais uma vez pode ser considerado um agente seguro 
que combate as infecções bacterianas, possuindo boas propriedades de penetração tecidual para o tratamento da acne. Assim a eficácia do óleo é empregada em formulações cosméticas auxiliando nos tratamentos estéticos.

\section{REFERÊNCIAS}

ACNE, 2008. Disponível em: www.acne.org/whatisacne.html. Acesso em: 28 nov. 2014.

AZEVEDO, Silberto. Óleo de Melaleuca ou Tea Tree Oil - Um poderoso antisséptico, germicida e fungicida natural. 2002. Disponível em: http://www.lemnisfarmacia.com.br/oleode-melaleuca-tea-tree-oil-um-poderosoantisseptico-germicida-e-fungicida-natural/ Acesso em:10 de novembro de 2014

BASSOLE, I.H.; JULIANI, H.R. Essential oils in combination and their antimicrobial properties. Molecules, v.17, n.4, p. 3989-4006. 2012.

BATISTUZZO, J.; ITAYA, M. et al. Formulário Médico Farmacêutico. 1 ed, p.333, 2000.

BAUMANN, Leslie. Dermatologia cosmética: princípios e práticas. Rio de Janeiro: Revinter, 2004.

CAMPBELL, I.; RAMOS-E-SILVA, M.; ASSUNÇÃO, B. F. G.; ZAITZ, C.; CARNEIRO, S.; CARDOSO, A.; PONZIO, H,; ALMEIDA, F. Estudo clínico aberto multicêntrico da efetividade e tolerabilidade do gel de adapaleno a $0,1 \%$ em pacientes com acne vulgar. Anais Brasileiros de Dermatologia, v. 78, n. 2, 2003.
CARSON, C. F.; HAMMER, K. A.; RILEY, T. V. Antimicrobial activity of essential oils and other plant extracts. Clinical Microbiology Reviews, v. 19, n. 1, p. 985-990, 2006.

DE SANTI, Erika. Dicionário de Princípios Ativos em Cosmetologia. São Paulo: Andrei, 2003.

GARCIA, C.C.; GERMANO, C.;OSTIL, N. M.;CHORILLI, M. Desenvolvimento e avaliação da estabilidade físico- química de formulações de sabonete liquido intimo acrescida de óleo de melaleuca. Rev. Bras. Fam. P. 236-240, 2009

GONTIJO. B.; PEREIRA, L. B.; SILVA, C. M. R. Antibióticos em Pediatria: Antimicrobianos na Prática Clínica Pediátrica - Guia Prático para Manejo no Ambulatório, na Emergência e na Enfermaria. Sociedade Brasileira de Pediatria. Rio de Janeiro, 2003.

GUTERRES, S. S.; ALVES, M. P.; POHLMANN,A.R.Polymeric anoparticles, monospheres and nanocapsules for cutaneous applications. Drug Target Insights, v. 2, p.147-157, 2007.

HABIF, P. T. Dermatologia clínica. $4^{\text {a }}$ ed., Porto Alegre: Artmed, 2005.

HEMIELEWSKI, C. Tratamentos medicamentosos eficazes nos casos de acne severa. Trabalho final (Graduação). Centro Universitário Franciscano, Santa Maria, 2008.

HÁLCON, L.; MIKUS, K. Staphylococcua aureus and wounds: a review of tea tree oil as a promising antimicrobial. Am J Infect Control. 2004 Nov

HERNANDEZ \& MERCIER-FRESNEL. Manual de Cosmetologia. $3^{a}$ ed.; Rio de Janeiro: Revinter, 1999. 
HOCHHEIM, L.; DALCIN, P.C.; PIAZZA, F.C.P. Princípios básicos para o tratamento cosmético da acne vulgar. UNIVALE, Santa Catarina: 2010.

LEBWOHE, M.; HEYMANN, W. R.; BERTH-JONES, J.; COULSON. I. Tratamento de doenças da pele: Estratégias terapêuticas abrangentes. $1^{\mathrm{a}}$ ed., São Paulo: Manole, 2004.

MALUF, S. Aromaterapia. São Paulo: [s.n.] 2009.

MARIN, F. O.; CARDOSO, L.E.; Formulação de um gel antiacne contendo óleo essencial de melaleuca. Univesidade Vale do Paraíba [s.d]

MARQUES. K. Acne: etiopatogenia, trabalho realizado na Escola Paulista de Medicina - UNIFESP, Rio de Janeiro, jan./fev. 2000.

MENESES, C.; BOUZAS, I. Acne vulgar na adolescência. Adolescência \& Saúde, volume $6, \mathrm{n}^{\circ} 3$, setembro, 2009.

MONDELLO, F; BERNARDIS, F; GIROLAMO, A et al. In vivo activity of terpinen-4-ol, the main bioactive component of Melaleuca alternifolia Cheel (tea tree) against azole-susceptible and resistant human pathogenic Candida species. BMC Infectious diseases, n. 6, 18, 2006.

PAWIN, H; BEYLOT, C; CHIVOT, $\mathrm{M}$ et al. Physiopathology of acne vulgaris: recent data, new understanding of the treatments. European Journal of Dermatology, n.14, p.1.4-12, 2004.

PEYREFITTE, G.; MARTINI, M.; CHIVOT, M. Cosmetologia, Biologia Geral e Biologia da Pele. São Paulo: Andrei Ltda, p. 39-43, 325-328, 1998.

PEREIRA, C.S.; BELO, R. S. A.; KHOURI, S.; CARDOSO, M. A. G.
Desenvolvimento de uma formulação farmacêutica utilizando óleo essencial de Melaleuca Alternifolia. XIII INIC, IX EPG E III INIC JR. UNIVAP, outubro/2009.

RANGEL, V. L. B. I. Desenvolvimento, estabilidade e liberação in vitro de preparações lipolíticas. Tese (Doutorado). Universidade de São Paulo, São Paulo, 1998.

RUSSEL, MF; SOUTHWEEL, IA. Monoterpenoid accumulation in 1.8 cineole, terpinolene and terpinen-4-ol chemotypes of Melaleuca alternifolia seedlings. Phytochemistry, v. 62, 683389, 2003.

RUZANY. M. et al. Rev. Adolescência e Saúde, Editada pelo núcleo de estudo da Universidade do Estado do Rio de Janeiro, v.1, n.2, junho de 2004 .

SÁ, C. M. D. Acne na mulher adulta: Avaliação entre 20 e 40 anos. Publicações Científicas, Rio de Janeiro, 2000.

SAMPAIO, S. A. P.; BAGATIN, E. Experiência de 65 anos no tratamento da acne e de 26 anos com isotretinoína oral. Anais Brasileiros de Dermatologia, v. 83, p. 361-367, 2008.

SAMPAIO, S.; RIVITTI, E. Dermatologia. São Paulo: Artes Médicas, 2001.

SETTE, I. M. F.; SILVA JÚNIOR, E. D.; BELÉM, L. F.; JANEBRO, D. I.; PEREIRA, G. J.S.; BARBOSA, J. A. A.; MENEZES, M. D. F. Isotretinoína no tratamento da acne: Riscos xbenefícios. Revista Brasileira de Ciências Farmacêuticas, v. 90, p. 186-189, 2009.

SOUZA, V. M.; ANTUNES JUNIOR, D. Ativos dermatológicos, guia de ativos dermatológicos utilizados na farmácia 
de manipulação para médicos e farmacêuticos. São Paulo: Pharmabooks, 2009.

SIMÕES, R. et al. Efeito do óleo de Melaleuca alternifólia sobre a infecção estafilocócica, Revista Lecta, Bragança Paulista: v. 20, n. 2, p. 143-152, jul./dez. 2002.

STRAUSS, JS; CHAIR, MD; KROWCHUK,MD et al. Guidelines of care for acne vulgarismanagement. Journal of Americam Academy of Dermatology, n. 56, p. 651-663, 2007.

TASHTOUSH, B. M.; JACOBSON, E. L.; JACOBSON, M. K. A rapid HPLC method forsimultaneous determination of tretinoin and isotretinoin in dermatological formulations. Journal of Pharmaceutical and Biomedical Analysis, v. 43, p. 859864, 2007.

TEIXEIRA, M. A. G.; FRANÇA, E. R. Mulheres adultas com acne: Aspectos comportamentais, perfil hormonal e ultrasonográfico ovariano. Revista Brasileira de Saúde Materno Infantil, v. 7, p. 39-44, 2007.

VAZ, A. Acne vulgar: Bases para o seu tratamento. Revista Portuguesa de Clínica Geral, v.19, p. 561-570, 2003. 